Int. J. Electrochem. Sci., 13 (2018) 11180 - 11192

International Journal of

ELECTROCHEMICAL

SCIENCE

www.electrochemsci.org

\title{
Electrochemical performance of Mg-Al-Zn and Mg-Al-Zn-Ce alloys as anodes for Mg-air battery
}

\author{
Hualong Zhu ${ }^{1,2}$, Hui Liu ${ }^{1,2}$, Hongjie Fang ${ }^{1,2}$, Yilong Dai ${ }^{2}$ Li Li $^{2}$, Xiangchun Xu ${ }^{2}$, Yang Yan ${ }^{1,2}$, \\ Kun $\mathrm{Yu}^{1,2, *}$ \\ ${ }^{1}$ Department of Materials Science and Engineering, Yantai Nanshan University, Yantai 265713, China \\ ${ }^{2}$ School of Materials Science and Engineering, Central South University, Changsha 410083, China \\ *E-mail: yukun2010@csu.edu.cn
}

doi: $10.20964 / 2018.11 .89$

Received: 22 July 2018 / Accepted: 5 September 2018 / Published: 1 October 2018

The microstructure of rolled annealed $\mathrm{Mg}-6 \% \mathrm{Al}-1 \% \mathrm{Zn}$ (AZ61) and $\mathrm{Mg}-6 \% \mathrm{Al}-1 \% \mathrm{Zn}-0.5 \% \mathrm{Ce}$ (AZ61Ce) alloys (wt.\%) was investigated by optical microscope (OM), scanning electron microscopy (SEM) and X-ray diffraction (XRD). The electrochemical and corrosion behaviors were studied by potentiodynamic polarization curve, electrochemical impedance spectroscopy (EIS) and hydrogen evolution test. The results show that the addition of Ce refines the grains of AZ61 alloy and promotes formation of $\mathrm{Al}_{11} \mathrm{Ce}_{3}$ phase. In addition, the AZ61Ce alloy exhibits better corrosion resistance than the AZ61 alloy, probably because the Ce can reduce the content of impurities (such as iron and nickel) and refine the grain of AZ61 alloy. When the two alloys were assembled into Mg-air battery, the AZ61Ce alloy exhibits significantly improved performance than the AZ61 alloy. This improvement in performance may due to the changes in alloy structure and composition. The refined grain and reduced impurities lower its self-corrosion and enhance its anode efficiency during discharge, the refined grains also lead to more grain boundaries, which provide more channels for the anode reaction, the refined grains and the existence of $\mathrm{Al}_{11} \mathrm{Ce}_{3}$ phase may together make the products film thinner and more porous during discharge, which result in easier contact of the electrolyte with the metal and a larger area of the anode reaction. This study shows that AZ61Ce alloy is an ideal anode material for Mg-air battery.

Keywords: Magnesium alloy; Microstructure characteristic; Corrosion behavior; Mg-air battery discharge performance

\section{$\underline{\text { FULL TEXT }}$}

(C) 2018 The Authors. Published by ESG (www.electrochemsci.org). This article is an open access article distributed under the terms and conditions of the Creative Commons Attribution license (http://creativecommons.org/licenses/by/4.0/). 